\title{
COMO CONSTRUIR UMA
}

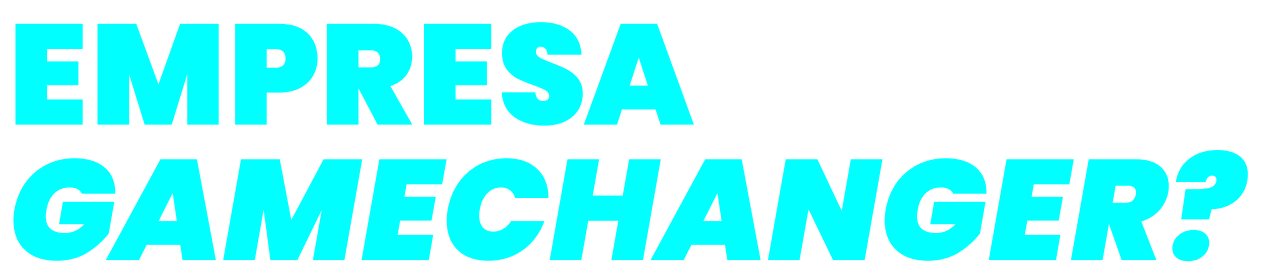

Rodrigo Pádua

Apple, Uber, Google, Netflix, entre outras, não só inovaram em seus negócios, mas mudaram o jogo. Ressignificaram seus setores causando um grande impacto no mercado e no dia a dia das pessoas. Mas qual é o perfil de quem está por trás de grandes cases como esses? Quais características eles têm em comum?

\section{UM PROPÓSITO DE PERTENCIMENTO}

Para começar, noto que eles têm um propósito de fazer a vida melhor, de forma relevante, motivados por um sentimento de pertencimento que vai além do dinheiro. Possuem um mindset de crescimento. São networkers, aproveitam o poder da rede digital e física para alcançar patamares exponenciais de atendimento aos clientes. Trabalham com outros atores e ecossistemas de forma colaborativa, sempre em uma visão de cocriação com os diferentes stakeholders.

Tomam decisões baseadas em dados e têm uma visão comercial muito forte, focada nos clientes. Buscam explorar ao máximo as tecnologias que os permitem ser mais eficientes e preditivos.

Os germechangers têm ownership e atucrm com autonomia, diferentemente do modelo "comando e controle", que já não funciona molis. São edpazes de descprender e recprender a todo tempo, incentivandoe proporeiondndo esse mesmo eprendizado pare o time.
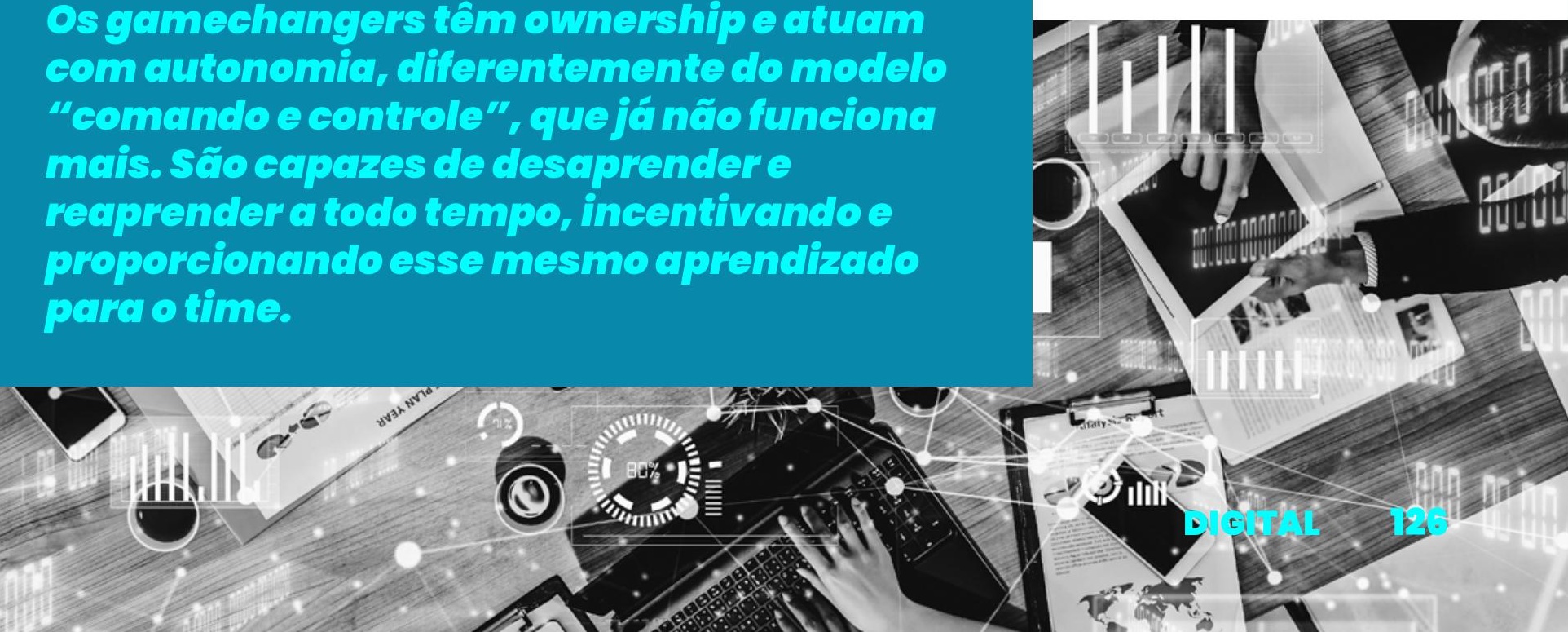
Fazem mais do que ser um superprofissional ou excelente executivo, pois, muitas vezes, tocam negócios que não estão redondos e bem ajustados e os transformam ou criam algo, demandando fortes características de empreendedorismo. Aprendem constantemente (lifelong learning) e têm sede pelo novo, pois sabem que a evolução é constante e cada dia mais rápida. Criam metas arrojadas, desafiadoras e, ao mesmo tempo, preocupam-se em cultivar um time forte e motivado, dentro de uma cultura saudável.

Gamechangers precisam também encontrar o lugar ideal para se desenvolverem, caso contrário não hesitarão em deixar a organização. Basta lembrar das histórias de algumas empresas bem-sucedidas para encontrarmos um CEO fantástico (a), sonhador (a), obsessivo (a), talentoso (a), com muita garra e que incentiva as características acima.

\section{UMA NOVA REALIDADE IMPULSIONADA POR GAMECHANGERS}

O mundo acelerou, a pandemia provocou um avanço espantoso em tecnologias digitais e inovação. E tudo isso é apenas o começo. Em breve, teremos a implementação do $5 G$ no Brasil, e a tendência é que as transformações deem um novo salto. A Internet das Coisas (IOT) permitirá a conexão de várias tecnologias. Imagine seu carro totalmente conectado com sua casa, sua geladeira ou com o delivery do supermercado?

A corrida mundial em relação à criação da vacina de COVID-19 deixará um legado positivo incalculável na descoberta de novas vacinas para outras doenças, na aceleração da transformação digital das empresas e na necessidade de um maior investimento dos governos na saúde preventiva.

Noséculo passado, durante o período pós-pandemia da gripe espanhola (1919), o mundo viveu um fenômeno forte de crescimento pautadoem uma alta liquidez e nos avanços em inovação. Tudo indica que viveremos novamente esse fenômeno.

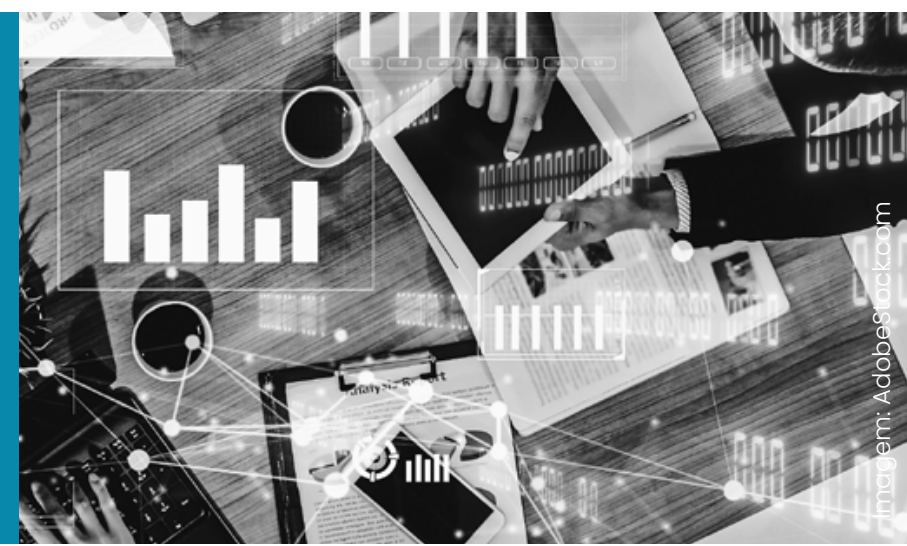

Os cientistas e intelectuais da época se encontravam em cafés, e havia toda uma troca de experiências e conhecimentos, que geravam novas ideias. Movimento este que, no mundo atual, é representado pelos coworkings, aceleradoras de startups e ventures, turbinados pela tecnologia e ferramentas de comunicação que nos conectam em redes no mundo inteiro. 


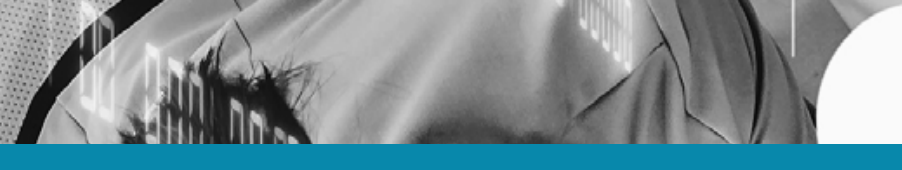

Tretid-se de uma nove realideder generalizade, que pede por

gomechangers em todas as esferas das emprescrs e soeiedade, em um movimento único de superç̧ãoe desenvolvimento.

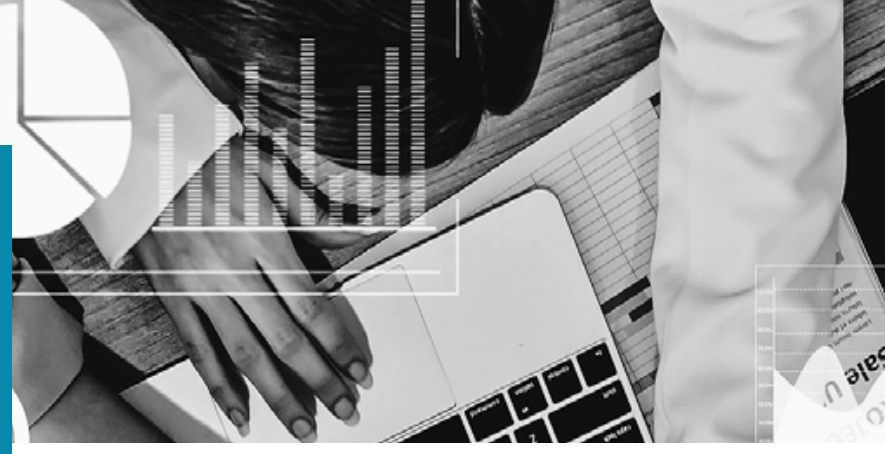

\section{GAMECHANGERS IMPULSIONAM O CRESCIMENTO NA STEFANINI}

Na Stefanini, viemos nos preparando para toda esta transformação digital há alguns anos. Por isto, enfrentamos a pandemia com um espírito de aprendizado e busca de oportunidades. Nada foi fácil, porém percebemos que nosso propósito - cocriar soluções para um futuro melhor - e nossas atitudes foram fundamentais para guiar a organização no momento em que vivemos.

A cultura da empresa, muito influenciada pelo perfil empreendedor de seu CEO e controladores, sempre foi pautada pelo incentivo às equipes de alta performance, para que elas pudessem alcançar, juntas, resultados coletivos diferenciados. Um dos pilares desta cultura se baseou no modelo de gestão por células que, além de proporcionar o sentimento de dono, deu espaço para a ação empreendedora.

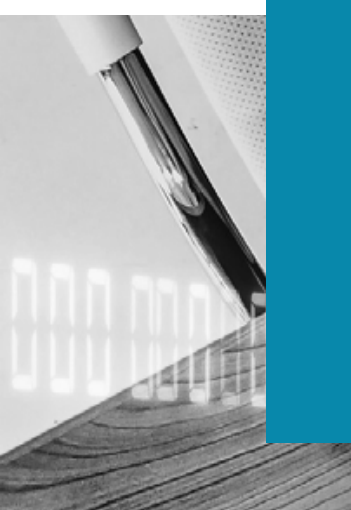

Trebollhor em um modelo de ecessistemd,

que inclui startups, ventures, universidades

e parceiros tombém foi fundermentel

parra eriar um ambiente propício co

desenvolvimento edtraģão de novos

gamechangers - um ambiente que incentiva

- erro em prol da experimentaçấ, por meio do

intrempreendedorismo, onde noves ideics são

levelntedes, elnellisedes e implentedes.
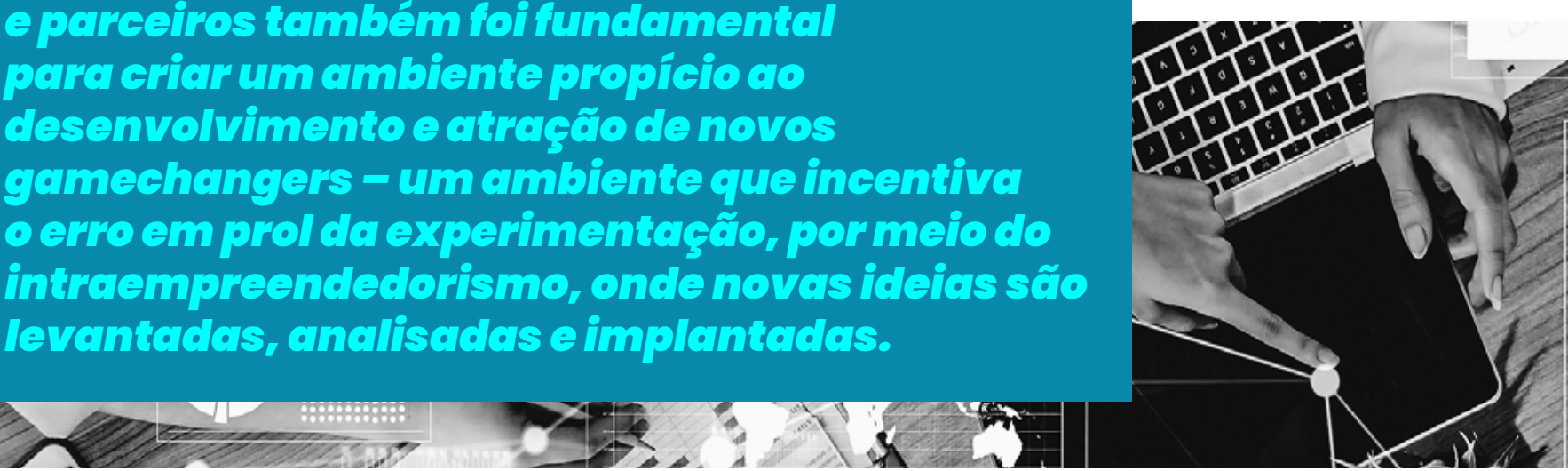

O Programa Insights, iniciativa que empodera os colaboradores a empreender, é bom exemplo neste sentido. Neste programa, o colaborador é incentivado a propor novos negócios, tendo liberdade para explorar todo o potencial do ecossistema, recebendo o apoio de mentores e do time de inovação durante todo o processo. 
Nossos escritórios, em todo o mundo, simbolizado pela nossa sala 87 (inovação), proporcionam serendipidades, que são encontros ocasionais entre as pessoas com conhecimento e formações diferentes (diversidade) e exaptação (uso de uma inovação previamente existente para uma nova função). Algumas destas ideias geram novas soluções ou novas empresas do grupo.

Nossas ventures, que poderiam ser comparadas a um modelo de corporate venture capital, são incorporadas ao grupo juntamente com os fundadores das empresas. Isto cria um aprendizado incrivel de novos olhares e novas tecnologias que se complementam. E o resultado disto? Novas ofertas, crescimento para os colaboradores e para a organização.

A área de Inovação da Stefanini tem o papel de orquestrar tudo isto, por meio de jornadas segmentadas que atendam às necessidades dos clientes e consumidores, utilizando de todo nosso portfólio de soluções.

Para sustentar esse ecossistema, criamos o modelo Stefanini Everywhere, possibilitando diferentes formas de trabalho: no escritório, remoto, híbrido e flexível, buscando democratizar as oportunidades de trabalho, sendo possivel contratar pessoas de qualquer lugar do Brasil e do mundo. Sabemos que, em um processo de transformação digital, a tecnologia não é o mais difícil, e sim a cultura, que é formada por pessoas com mindset de crescimento.

O Stefanini Everywhere proporciona uma democratização das oportunidades de trabalho. Ao mesmo tempo em que um colaborador pode viver em uma pequena cidade do interior do país, no conforto da sua família e cultura, ele tem a oportunidade de trabalhar em uma empresa global, com muita diversidade, presente em 41 países, com cerca de 27 mil colaboradores, onde aproximadamente 11 mil estão fora do Brasil, o que nos coloca entre as cinco empresas mais internacionalizadas do Brasil. O programa nos possibilitou escalar nossa capacidade de encontrar e contratar novos gamechangers.

Desde que o programa Everywhere foi criado, cerca de 1.000 pessoas foram contratadas em algum dos modelos flexíveis, sendo 700 no Brasil e 300 em países como Romênia, Estados Unidos, Colômbia e Peru. No Brasil, temos profissionais da Suíça e Peru atuando em projetos locais.

Inicialmente criado devido à pandemia, percebemos que os novos modelos de trabalho melhoraram nossa produtividade, qualidade (NPS) e engajamento (e-NPS). Por isso, definimos que 50\% dos colaboradores não voltarão a trabalhar no escritório e estarão em um dos modelos descritos.

Toda a jornada do colaborador é digital, da atração até a trilha de carreira, uma estrada longa e de evolução constante. Combinamos tecnologia, desenvolvida internamente, com startups de mercado, onde trabalhamos o employer branding (marca empregadora), a atração, o onboarding (admissão e integração), a comunicação, o treinamento e o mentoring, utilizando conceitos de colaboração e gamificação. 
Utilizamos ferramentas e testes de perfil técnico e cultural nos nossos processos de recrutamento, buscando candidatos que tenham "matching" com esse perfil empreendedor e disruptivo, também estimulado pela diversidade de olhares e culturas, já que a empresa está em 41 países.

Em resumo, a jornada digital envolve quatro momentos na gestão do ciclo de vida do colaborador:

1. Recrutamento e seleção com Inteligência Cognitiva \& IA: As assistentes virtuais, como a Sophie, desenvolvida pela Stefanini, realizam o primeiro contato com os candidatos que se encaixam no perfil de uma determinada vaga respondendo questões durante todo o processo seletivo, que chamamos de "fase namoro", e direcionando aos motores de Matching do Virtual Assistent, que avalia as competências necessárias e indica maior fit para a vaga.

2. Disseminação da cultura da empresa: De forma simples, o Onboarding Digital integra Service Designer/UX/UI e Inteligência de dados \& IA. Por meio dessas ações se estabelece uma experiência dinâmica, transparente e responsável. E, claro, aumentando também o índice de permanência do colaborador que, segundo Aberdeen Group, pode aumentar em até 50\%.

3. Retenção de talentos: Através da plataforma personalizada que criamos na Stefanini, os profissionais de RH podem ter a visão de todos os colaboradores alocados em clientes para projetos específicos. Caso o projeto seja finalizado, o time pode realocá-lo em novos clientes e projetos.

4. Suporte: A troca de experiências com colaboradores mais antigos é fundamental para que entendam processos, além de aumentar o censo de pertencimento e estimular o crescimento profissional. O formato de mentoria é um exemplo clássico de aprendizagem pelo exemplo, que facilita, incentiva e inspira os profissionais envolvidos, além de proporcionar uma performance ainda mais produtiva.

Vale ressaltar que, para o desenvolvimento da plataforma tecnológica, a Stefanini usou componentes que integram seu ecossistema de Ventures (empresas do Grupo), assim como a agilidade do laboratório de inovação da área de People \& Culture, que conduziu todo o ciclo de vida de desenvolvimento das iniciativas e da implementação efetiva das estratégias do modelo. Com sessões de mapeamento das jornadas dos colaboradores, estudo das novas características e dinâmicas remotas trazidas ao cenário a partir da pandemia, prototipação e validação das ideias de soluções, foi criada a jornada completa. 
Com o objetivo de acelerar a formação de uma nova geração de líderes gamechangers, criamos o programa de potenciais, que é dividido entre estagiários (cursando a faculdade), trainees (recém-formados) e, mais recentemente, digital leader (jovens com 3-5 anos de formados). Todos esses jovens passam por uma seleção criteriosa e recebem um treinamento teórico e prático, com muita mentoria para assumirem novos desafios no futuro.

\section{DESENVOLVENDO GAMECHANGERS}

\section{Perre a formaģão de gelmechcingers, é preciso entender} que esscs pesseas sempre têm um papel forte de lílerenģ, बjudam a mover vátrios outros rumo a um destino, sc̃o audccioses e visionćtrios. Além disso, têm uma forte resillêncic e visăo otimista, pois, na jornade de construção, nem sé de vitórias viverão es coleborcdores.

Neste sentido, é preciso criar um ambiente que permita o erro e o aprendizado constante. Quanto mais aberta for a rede de relações internas e externas, mais espaço para a inovação e intraempreendedorismo será criado.

Mesmo que perte ders helbilidcres des gemecherngers seja um componente de seu períl, outras podem ser desenvolvidas e aperfeiçoaders, seja através de programas de formação internos ou com eppoio de pareeiros educceioncils. Não menos importante é estruturer os incentivos (fincheeiros ou não) corretos que reforeem o trebalho em time, formaģês de noves tellentos e uma eultura de done.

Cabe a cada um de nós identificar esses perfis, estimular aqueles que são naturalmente gamechangers ou que desejam assumir essa postura dentro das organizações, treinálos e encorajá-los a assumir, cada vez mais, esse papel de transformadores da visão organizacional para construir um futuro repleto de possibilidades para a comunidade interna e externa. Esse é o papel das empresas com mindset de crescimento e que apostam na inovação como forma de transformar o mundo de maneira colaborativa e sustentável. 


\section{Rodrigo Pádua}

Rodrigo Pádua é vice-presidente de Gente e Cultura da Stefanini desde abril de 2019, sendo responsável global por todos os processos de RH (Brasil, Latam, USA e Europa), com atuação também em transformação digital e cultural, employer branding e atração de talentos, aprendizagem e performance.

Conta com uma jornada de aprendizados em planejamento estratégico, turnaround e implementação de propósito e valores (Cultura); preparação de companhias para abertura de capital (IPO Bovespa, NYSE); gestão de todos os processos de Gente (recrutamento, treinamento, desenvolvimento, avaliação, liderança, engajamento, remuneração e comunicação); liderança no Comitê de Pessoas e Remuneração (Conselho de Administração); membro do Conselho de Sustentabilidade; implementação de startups para a melhoria dos processos de RH (Gupy, Workplace, ClubeBen). Trabalhou anteriormente em empresas como Grupo JSL SA, BRF, Gafisa, Danone e Ambev.

É formado em Administração, com MBA em Recursos Humanos pela Fundação Getúlio Vargas (FGV) e em Negócios pelo Ibmec.
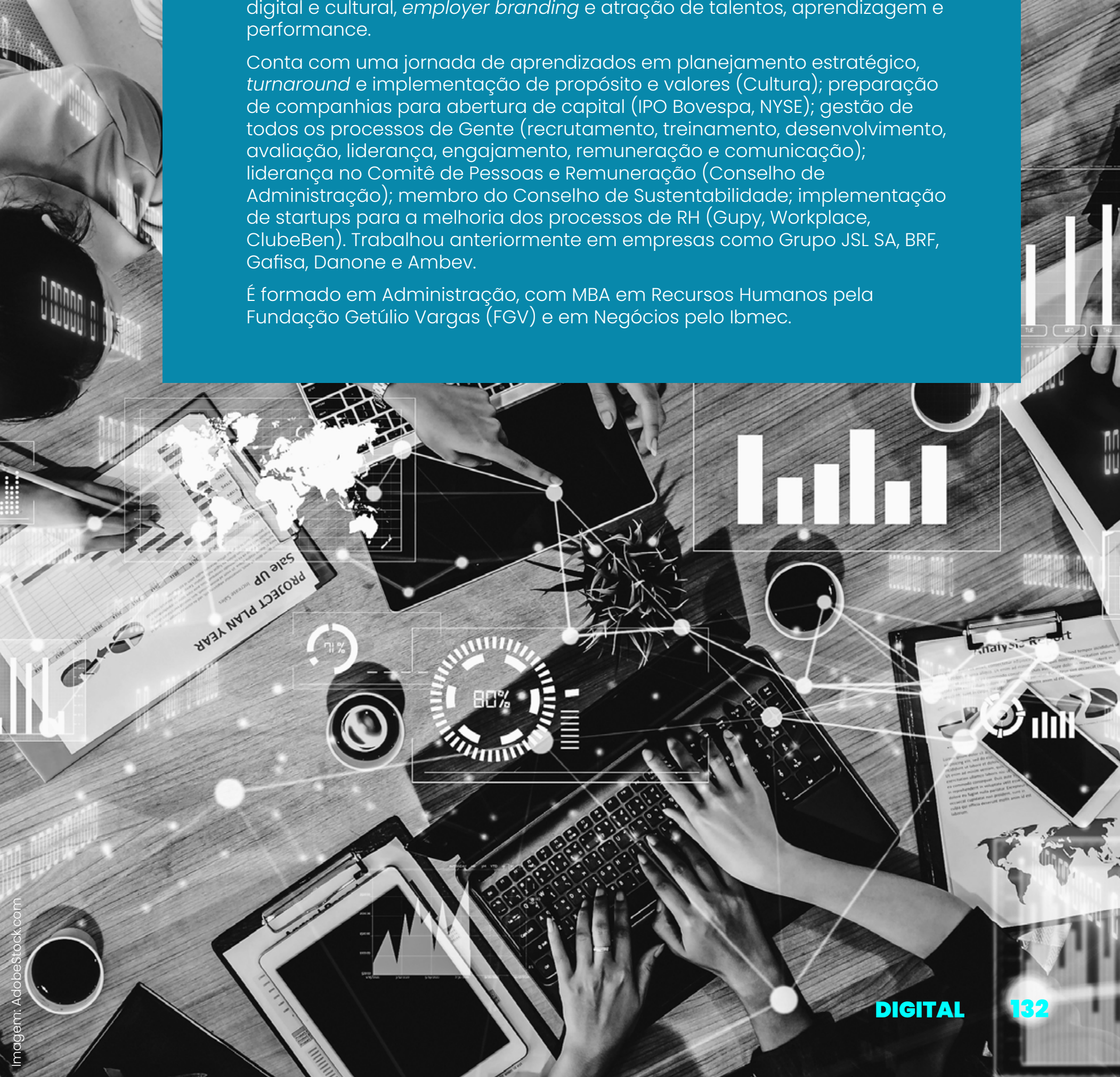
-
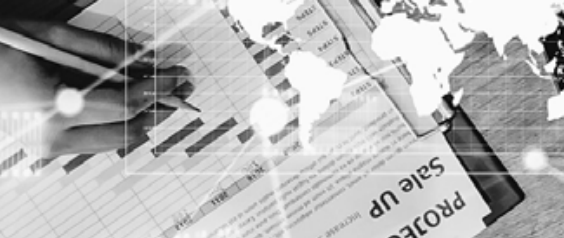

8
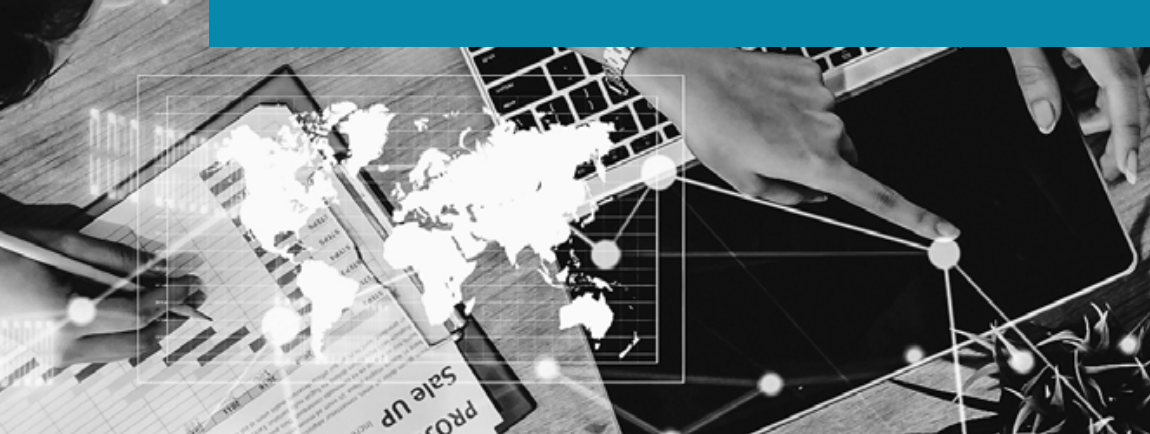

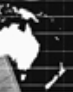
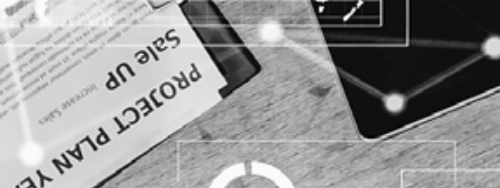